\title{
Horticultural Value of Wild Genetic Resources-Introduction to the Workshop
}

\author{
Gayle M. Volk ${ }^{1}$ and Christopher M. Richards \\ National Center for Genetic Resources Preservation, U.S. Department of Agriculture, 1111 S. Mason Street, \\ Fort Collins, CO 80521
}

Additional index words. genebank, genetic diversity, breeding

\begin{abstract}
Wild plant genetic resources are increasingly becoming valuable for breeding, genomics, and ornamental horticulture programs. Wild relatives of horticultural species may offer desirable traits that are not available in cultivated varieties, but "wilds" often also have traits that are highly undesirable. Advances in comparative genomics and markerassisted breeding facilitate the inclusion of the valued traits from wild materials in plant breeding programs. As technologies advance, wild plant genetic resources will become even more valuable for future research developments. This serves as an introduction to a series of proceedings articles from the American Society of Horticultural Science meetings in 2010 workshop entitled "Horticultural Value of Wild Genetic Resources."
\end{abstract}

The role of wild germplasm in agricultural breeding is undergoing a profound change. The wide use of genomic-level characterization data has changed the way breeders can access and exploit the diversity within these accessions. Both low-cost sequencing methods and new analytical approaches are providing whole genome characterization beyond the model crop species. The prospect of developing high-density single nucleotide polymorphism (SNP) markers in highly diverse accessions of wild relatives opens up the opportunity to understand genetic history of domestication events and will also provide key insight into loci that underpin agriculturally important traits.

Assessments of genetic diversity in wild collections reveal evidence of historical demography and natural selection. This diversity has critical value to both phylogenetic and evolutionary studies of species relationships and population structure. Genebanks provide this diversity as well-documented viable seeds or living plants often collected from multiple locations within a species range (Walters et al., 2008). Availability of living plants provides the option of genetic introgression of wild-type loci into a cultivated background. Importantly, characterization of the functional diversity at agronomically important loci allows for the identification of novel allelic variants as targets for marker-assisted breeding.

Evaluation trials provide insights into observed medicinal, nutritional, yield, quality, and resistance traits for possible use in breeding. Allele mining lets breeders specifically select alleles of interest and avoid introgression of less desirable alleles that can be found in wild materials. In addition, com-

Received for publication 7 Mar. 2011. Accepted for publication 28 Mar. 2011.

This paper was part of the workshop "Horticultural Value of Wild Genetic Resources" held 3 Aug. 2010 at the ASHS Conference, Palm Desert, CA, and sponsored by the Genetics and Germplasm (GG) Working Group.

${ }^{1}$ To whom reprint requests should be addressed; e-mail Gayle.Volk@ars.usda.gov. parative genomics can identify new gene complexes or regulatory factors that affect breeding strategy and approaches for more rapid improvements. With the greater availability of genetic markers, marker-assisted breeding has become a reality (Fan et al., 2010; Varshney and Dubey, 2009). However, the broad applicability of these methods is hampered by gaps in the phenotypic characterization of wild accessions. The potential quality improvements resulting from the incorporation of wild alleles with unknown function into known cultivars is just beginning to be recognized (Zhao et al., 2010).

This workshop on the "Horticultural Value of Wild Plant Genetic Resources" was held at the 2010 American Society for Horticultural Science Annual Conference in Palm Desert, CA, and was organized by the Genetics and Germplasm Working Group. The objectives of the workshop were to 1) identify the value of using wild genetic resources in breeding and research programs; 2) provide examples of highly successful plant explorations; 3 ) demonstrate the uses of wild relatives of horticultural crops in genomics; and 4) explain exploration opportunities available through the USDA Plant Exploration Program. Each of the six presentations has been made available at $<$ http://www.ashs.org/ index.php?option=com_content\&view $=$ article \& id=201:2006-2010-horttalks-presentations\& catid $=44$ : conference-presentations $\&$ Itemid $=$ $146>$.

Workshop participants are plant explorers who have traveled throughout the world to select novel and representative plant materials for inclusion in the USDA-ARS National Plant Germplasm System collections. The workshop speakers highlighted the novelty and diversity available in wild plant genetic resources both within the United States and abroad. They demonstrated how wild germplasm is a key resource for horticultural improvement.

Speakers were selected based on their significant contributions to the development of valuable horticultural collections in the United States. Their explorations demonstrate both the challenges and the positive outcomes from trips focused on ex situ conservation of horticultural crops. The first speaker, Barbara
Hellier, USDA-ARS-Western Regional Plant Introduction Station, Pullman, WA, focused on the process of organizing and participating in USDA-ARS Plant Exploration Officesponsored plant expeditions. She highlighted her 2008 trip to Central Asia to collect a wild relative in the lettuce family, Russian dandelion, of interest in the development of alternative rubber products. Next, Kim Hummer, USDA-ARS National Clonal Germplasm Repository, Corvallis, OR, and Arctic and Subarctic Plant Gene Bank, Palmer, AK, described some of the new strawberry (Fragaria), currants and gooseberries (Ribes), raspberries and blackberries (Rubus), and blueberries and cranberries (Vaccinium) species that she and her colleagues have collected from the Pacific basin, South America, Europe, and Asia. The crop wild relatives are of interest taxonomically as well as for improvement in plant adaptation to cold and warm environments, yield, and antioxidant content in new cultivars released from university and federal berry breeding programs. Richard Campbell, Fairchild Tropical Botanical Garden, Homestead, FL, provided attendees with an adventure travelogue of explorations focused on the West Indian avocado (Persea americana var. americana), jackfruit (Artocarpus heterophyllus), mamey sapote (Pouteria sapota), sapodilla (Manikara zapota), canistel (Pouteria campechiana), abrico (Mammea Americana), tamarind (Tamarindus indica), and Spanish lime (Melicoccus bijugatus). His collection trips have made many new tropical crop cultivars with novel flavors, textures, and colors available to American consumers in collections maintained by the Fairchild Tropical Botanical Gardens.

The program then switched its emphasis from collection trips to that of wild germplasm. John Bamberg, USDA-ARS US Potato Genebank, Sturgeon Bay, WI, began with his work determining the relationship between wild-collected potato (Solanum fendleri and $S$. jamesii) in the southwestern United States and that of the cultivated potato (Solanum tuberosum). He emphasized the value of collecting accurate georeferencing data during trips to that repeated visits so small populations can capture genetic shifts in population 
structure over time. Dr. Bamburg also provided examples of how wild potatoes have provided novel forms of disease and pest resistance and improved nutritional traits for breeding programs. Phil Simon, USDA-ARS Vegetable Crops Research Unit, Madison, WI, has collected wild carrot relatives (Daucus sahariensis) and garlic (Allium sativum) from Africa and Central Asia. The wild carrots have nematode resistance and nutritionally valuable carotenoids and anthocyanins. Some wild garlics can produce true seeds, a trait of great interest to the garlic industry to reduce production costs. Our final speaker, Ray Schnell, USDA-ARS Subtropical Horticulture Research Station, Miami, FL, emphasized his marker-assisted breeding program for cacao (Theobroma cacao). Cupuassu (Theobroma grandiflorum) is a wild relative of cacao that exhibits resistance to specific isolates of witches' broom disease (Moniliophthora perniciosa). Hybrid populations between cacao and cupuassu are being developed as part of a genetic improvement program for cacao.

Many future improvements in agricultural yield and quality will depend on having welldocumented wild plant genetic resources available to the horticultural community through genebanks and other conservation programs. Wild materials, characterized by genotype and phenotype, will become even more valuable as genomic tools make allele mining and markerassisted breeding common within breeding programs.

\section{Literature Cited}

Fan, S., D.G. Bielenberg, T.N. Zhebentyayeva, G.L. Reighard, W.R. Okie, D. Holland, and
A.G. Abbott. 2010. Mapping quantitative trait loci associated with chilling requirement, heat requirement and bloom date in peach (Prunus persica). New Phytol. 185:917930.

Varshney, R.K. and A. Dubey. 2009. Novel genomic tools and modern genetic and breeding approaches for crop improvement. J. Plant Biochem. Biotechnol. 18:127-138.

Walters, C., G.M. Volk, and C.M. Richards. 2008 Genebanks in the post-genomic age: Emerging roles and anticipated uses. Biodiversity 9:6871.

Zhao, K.Y., M. Wright, J. Kimball, G. Eizenga, A McClung, M. Kovach, W. Tyagi, M.D. Ali, C.W. Tung, A. Reynolds, C.D. Bustamante, and S.R. McCouch. 2010. Genomic diversity and introgression in $O$. sativa reveal the impact of domestication and breeding on the rice genome. PLoS ONE (5):e10780, doi: 10.1371/ journal.pone. 0010780 . 